\title{
Cytomegalovirus and invasive fungal disease: trolls of hematopoietic cell transplantation
}

\author{
Lidia Gil \\ Department of Hematology and Bone Marrow Transplantation, University of Medical Sciences, Poznan, Poland
}

Progress in hematological oncology over last 50 years can be measured in the improvement in overall survival. This has been achieved by multiagent chemotherapy, immunotherapy including cellular therapy, and targeted therapy [1, 2]. These achievements were made possible by a combination of excellent everyday multidisciplinary and clinical work with national and international cooperation. Supportive therapy based on prevention and treatment of complications is essential in hematological oncology and hematopoietic cell transplantation [3, 4].

In this issue of Acta Haematologica Polonica, Styczyński et al. [5] present eight years of their pediatric experience detailing a continuous fight against fungal infections after hematopoietic cell transplantation or conventional therapy. No-one should be surprised that the incidence of invasive fungal disease (IFD) was highest in patients with acute leukemias, exceeding 50\% in acute myeloid leukemia (AML) and reaching $30 \%$ in acute lymphoblastic leukemia (ALL). Similarly, no one should be surprised that graft-versus-host disease (GvHD) is a risk factor for the development of IFD.

But their study also provided strong evidence that cytomegalovirus (CMV) replication predisposes to the development of IFD, with mortality of over $20 \%$. What can be done about this? We must prevent both IFD and the occurrence of risk factors, namely CMV and GVHD [6-8]. It seems to be easy for CMV to reactivate with the almost perfect prophylactic drug letermovir [9]. Better GvHD prevention will require however even greater scientific and clinical efforts.

Progress in medicine starts with prophylaxis!

\section{Author's contributions}

$L G$ - sole author

\section{Conflict of interest}

None

\section{Financial support \\ None.}

\section{Ethics}

The work described in this article has been carried out in accordance with The Code of Ethics of the World Medical Association (Declaration of Helsinki) for experiments involving humans; EU Directive 2010/63/EU for animal experiments; Uniform Requirements for manuscripts submitted to Biomedical journals.

\section{References}

1. Jędrzejczak WW. Polish hematology: from here to the future. Acta Haematol Pol. 2021; 52(1): 2-3, doi: 10.5603/AHP.2021.0002.

2. Giebel $\mathrm{S}$, Basak G, Bieniaszewska M, et al. Current status and achievements of Polish haemato-oncology. Acta Haematol Pol. 2021; 52(1): 4-17, doi: 10.5603/AHP.2021.0003.

3. Styczynski J, Tridello G, Gil L, et al. Prognostic impact of Epstein-Barr virus serostatus in patients with nonmalignant hematological disorders undergoing allogeneic hematopoietic cell transplantation: the study of Infectious Diseases Working Party of the European Society for Blood and Marrow Transplantation. Acta Haematol Pol. 2020; 51(2): 73-80, doi: 10.2478/ahp-2020-0015.

4. Czyżewski K, Sedláček P, Štěrba J, et al. Progress and trends in pediatric hematopoietic cell transplantation in Central-East European countries. Acta Haematol Pol. 2020; 51(3): 142-150, doi: 10.2478/ ahp-2020-0026.

5. Styczyński J, Gałązka P, Czyżewski K, et al. High risk of invasive fungal disease in children undergoing hematopoietic cell transplantation or complex anticancer therapy: the adverse role of post-transplant CMV replication. Acta Haematol Pol. 2021; 52(5): 483-492. doi: 10.5603/ AHP.a2021.0025.

6. Gil L, Kałwak K, Piekarska A, et al. Antifungal management in adults and children with hematological malignancies or undergoing hematopoietic cell transplantation: recommendations of Polish Society of Hematology and Blood Transfusion, Polish Society of Pediatric Oncology

\footnotetext{
Address for correspondence: Lidia Gil, Department of Hematology and Bone Marrow Transplantation, University of Medical Sciences, Szamarzewskiego 84, 60-569 Poznań, Poland, e-mail: lidia.gil@skpp.edu.pl
}
PTH:T copyright $\odot 2021$
The Polish Society of Haematologists and Transfusiologists, Insitute of Haematology and Transfusion Medicine.
七ढ़ All rights reserved.


and Hematology, and Polish Adult Leukemia Study Group, 2020. Acta Haematol Pol. 2020; 51(2): 60-72, doi: 10.2478/ahp-2020-0014.

7. Styczyński J, Czyżewski K, Frączkiewicz J, et al. Clinical spectrum and outcome of invasive mucormycosis in children and adults: Polish experience of the decade 2010-2019. Acta Haematol Pol. 2020; 51(3): 157-163, doi: 10.2478/ahp-2020-0028.

8. Styczyński J, Czyżewski K, Ussowicz M, et al. Antimicrobial prophylaxis in patients after hematopoietic cell transplantation: results of a survey of the Polish Federation of Bone Marrow Transplant Centers. Acta Haematol Pol. 2020; 51(3): 183-186, doi: 10.2478/ ahp-2020-0032.

9. Czyżewski K, Styczyński J. Real-world experience with letermovir in primary prophylaxis of cytomegalovirus in adult patients after hematopoietic cell transplantation: summary of reported data. Acta Haematol Pol. 2021; 52(3): 182-189, doi: 10.5603/ AHP.2021.0035. 